\title{
EFFECT OF DIFFERENT ENERGY LEVELS OF RADIAL SHOCK WAVE THERAPY ON SPASTICITY IN PATIENTS WITH STROKE
}

\section{Khaled Z. Fouda *1, Waleed T. Mansour ${ }^{2}$.}

${ }^{* 1}$ Lecturer of Physical Therapy, Basic Science for Physical Therapy Department, Faculty of Physical Therapy, Cairo University, Egypt.

${ }^{2}$ Professor of Physical Therapy for Neurology and Neurosurgery, Faculty of Physical Therapy, Cairo University, Egypt.

\section{ABSTRACT}

Background and purpose: Spasticity in the hands and a wrist is a major problem in the management of stroke patients. Different energy levels of shock wave therapy (SWT) have been used for treatment of spasticity. So, the purpose of the study was to compare the effect of two different energy levels of radial SWT on spastic muscles of the hand and wrist in patients affected by stroke.

Materials and Methods: Patients randomly assigned into two groups. Group A received the low energy radial SWT while group B received the medium energy radial SWT. Spasticity of wrist and fingers was evaluated using Modified Ashworth Scale (MAS), range of motion (ROM) of the wrist was evaluated using digital goniometer and pain was measured by Visual Analogue Scale (VAS).

Results: there was a significant decrease in MAS scores of the wrist flexors and fingers flexors muscles post treatment for both groups $(P<0.05)$. The ROM was significantly increased post treatment from $(48.46 \pm 2.09)$ to $(70.02 \pm 3.23)$ for group A and from $(49.15 \pm 1.95)$ to $(79.13 \pm 3.42)$ for group B. Also VAS scores was a significantly decreased in both groups post treatment.

Conclusion: Radial SWT is an effective therapeutic tool in reducing flexor spasticity of the wrist and hand in patients with stroke. Moreover, the medium energy level was superior to the low energy level in regarding to the measured treatment outcomes.

Key words: Energy levels, Radial shock wave, Spasticity, Stroke.

Address for correspondence: Dr. Khaled Z. Fouda (PhD, PT); 7 Ahmed El Zayat Street, Bein El Sarayat, Giza 12612, Egypt. E-Mail: kzfouda2004@yahoo.com

Access this Article online

Quick Response code

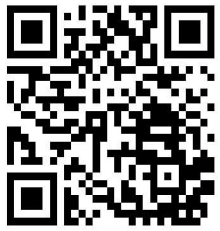

DOI: $10.16965 /$ ijpr.2017.264

Journal Information

International Journal of Physiotherapy and Research

ICV for 2016 ISSN (E) 2321-1822 | ISSN (P) 2321-8975

86.93 https://www.ijmhr.org/ijpr.html

DOI-Prefix: https://dx.doi.org/10.16965/ijpr

Article Information

Received: 12 Dec 2017

Peer Review: 12 Dec 2017

Revised: None
Accepted: 15 Jan 2018

Published (O): 11 Feb 2018

Published (P): 11 Feb 2018

\section{INTRODUCTION}

Stroke is a leading cause of long-term disability in adults. It is one form of upper motor neuron lesions which are characterized by lack of cortical drive leading to disorganization of the motor output for the muscles in the form of lack of descending excitatory impulses to these muscles [1,2]. Hemiplegia due to stroke accounts for the majority of admissions to the rehabilitation clinics [3].
Spasticity, which is a component of the upper motor neuron syndrome, is a neurological symptom frequently appearing in stroke patients and is defined as a velocity dependent increase in muscle tone with exaggerated tendon reflexes. It has been reported that spasticity appears in approximately $35 \%$ of stroke patients [2].

Increase in muscle tone in the hands and a wrist is a major problem in the management of chronic hemiparetic patients and may seriously impair 
dressing, washing, and other activities of daily living. Muscle hypertonia will produce a series of complications causing changes in the components of muscles and subsequent stiffness in tendons and joints [4].

Different treatment methods have been used for treatment of spasticity include physical therapy, oral anti-spastic drugs, chemical nerve block and motor point block using phenol or ethyl alcohol and botulinum toxin injection $[5,6]$. It has been reported that muscular injections of botulinum toxin type $A$ decreases muscular tone in hypertonic muscles of the hand, with improvement in the use of the upper limb and a decrease in complications [7-10]. However, the development of neutralizing antibodies can reduce the efficacy of treatment. In addition, the dosage of botulinum is not always sufficient to treat extensive and severe hypertonia in upper and lower limbs [11].

The necessity of new noninvasive treatment methods for spasticity has been raised because spasticity cannot be controlled sometimes even with diverse treatment methods as well as due to the existing side effects of oral drugs and the invasiveness of local treatment methods [12]. Recent studies indicated that shock wave therapy (SWT) is an effective method for treating spasticity, it is being considered as a new alternative treatment method for spasticity [1318]. The radial SWT is a new noninvasive alternative therapeutic method based on technology generating non-focused shockwaves. It doesn't require anesthesia or analgesics with high comfort of the therapy, also it does not cause muscle weakness in patients with stroke [19-22].

The most important parameter of SWT for the outcome of treatment is the energy [23]. Different energy levels have been used in the previous studies for treatment of spasticity without any proven clinical benefits for certain energy level over the other [13-22]. So, the purpose of the study was to compare the effect of two different energy levels of radial SWT on spastic muscles of the hand and wrist in patients affected by stroke.

\section{MATERIALS AND METHODS}

Participants: Forty male patients having upper limb spasticity post stroke were recruited for the study from neurological outpatient clinics of Cairo University hospitals and National Institute of Neuromotor System Cairo Egypt, their age were ranged from (40-65) years. Patients were randomly assigned into two equal groups, with the following inclusion criteria: first time unilateral stroke with hemiparesis, the duration of illness were at least three months post stroke, eligible patients had spasticity of the wrist flexor and fingers flexors exceeding 1+ on the Modified Ashworth Scale (MAS) [11], medically stable and able to understand the instruction. Localization of the lesion was proved by Computed Topography and/or magnetic resonance imaging.

Patients were excluded if they had prior treatment of the upper limb with any botulinum toxin serotype or with phenol, alcohol, or surgery and any known contraindications for radial SWT. The research design was randomized, single-blinded clinical trial. Randomization was performed by a statistician who was blinded to the study treatment and procedures' details. It was performed simply by adding a specific identification number for each patient. A SPSS program (version 20) was used to randomly assign the patients into two equal groups $(n=20)$. A written informed consent in accordance with the Declaration of Helsinki was signed by each participant before the beginning of the study. Confidentiality and anonymity of patient's data was considered and they have the right to withdraw from the study at any time.

\section{Outcome measures}

Passive wrist range of motion: Digital goniometer was used to evaluate the passive range of motion (ROM) of the wrist. The digital goniometer has adequate concurrent criterion-related validity as a tool for assessment of joint ROM and equivalent inter- and intra-rater reliability to the universal goniometer [24]. Passive ROM of the wrist was measured pre and post treatment by measuring the angles of the maximum flexion and the maximum extension and summing up the angles using digital goniometer [12]. Pain intensity: Visual Analogue Scale (VAS) was used to assess pain intensity. It consists of a $10-\mathrm{cm}$ straight line anchored at one end by a label such as "no pain" and at the other end by 
a label such as "the worst pain imaginable". It was reported as valid and reliable tool for pain assessment $[25,26]$. Pain intensity were measured during passive ROM evaluation of the wrist in extension pre and post treatment. The patient was instructed to simply mark the line to indicate pain intensity and the provider then measures the length of the line to the mark on the scale.

Spasticity of wrist and fingers: The MAS from 0 to $4(0=$ No increase in muscle tone to $4=$ Affected part(s) rigid in flexion or extension) was used to assess spasticity. It was reported as valid and reliable tool for assessment of spasticity $[27,28]$. Spasticity of wrist and fingers were measured pre and post treatment using MAS, for convenience in the statistical analysis, MAS $1+$ was substituted by 2 , and 2,3 , and 4 were substituted by 3,4 , and 5 , respectively [12].

Procedures: All patients were treated with the traditional physical therapy program which consisted of appropriate positioning of the extremities, mobility training, range of motion exercises, passive stretching exercise, standing up and balance training, and also training of daily living activities to improve functional status. Patients were randomly assigned into two equal groups. Group A: Twenty patients were treated with traditional physical therapy program plus radial SWT which consisted of 2 bar intensity (low energy level), 1500 shots were used to treat flexor muscles of the forearm and 3200 shots for palmar interosseus muscles of the hand ( 800 shots for each muscle) at a frequency of $8 \mathrm{~Hz}$. Group B: Twenty patients were treated with traditional physical therapy program plus radial SWT which consists of 4 bar intensity (medium energy level), 1500 shots were used to treat flexor muscles of the forearm and 3200 shots for palmar interosseus muscles of the hand ( 800 shots for each muscle) at a frequency of $8 \mathrm{~Hz}$. Radial SWT was given one session per week for four weeks for both groups. Intellects ${ }^{\circledR}$ RPW Shockwave by Chattanooga Corporation was used to deliver stimulation to the spastic muscle. It has the following technical specifications; compressed air output (1.4 - 5) bars, frequency $(0.5-21 \mathrm{~Hz})$, pulses or shots $(10-10,000)$, size of applicator $15 \mathrm{~mm}$ and penetration depth $(0-50 \mathrm{~mm})$. It has unique optimal energy level adjustment feature that allows gradual ramping of the intensity during treatment which provide inherent safety as demonstrated by the manufactures guidelines.

Statistical analysis: Data analysis was performed by SPSS (Version 20) for Windows. Descriptive statistics including the mean and standard deviation was used to describe general characteristics of subjects and outcome variables. Student-t-test was used to determine significant differences between groups. The P-value $<0.05$ was taken as significant.

\section{RESULTS}

Participants characteristics of both groups presented in table (1). There were no significant differences between both groups regarding age, body mass index (BMI) and duration after stroke onset as ( $P>0.05)$.

Table 1: Demographic characteristics of participants.

\begin{tabular}{|c|c|c|c|}
\hline General Characteristics & Group (A) & Group (B) & Comparison \\
\cline { 2 - 4 } & Mean \pm SD & Mean \pm SD & P-value \\
\hline Age (year) & $54.47 \pm 3.85$ & $55.25 \pm 4.05$ & 0.536 \\
\hline $\begin{array}{c}\text { Body mass } \\
\left.\text { index(Kg/m }{ }^{2}\right)\end{array}$ & $26.33 \pm 2.12$ & $27.22 \pm 2.36$ & 0.217 \\
\hline $\begin{array}{c}\text { Duration after stroke } \\
\text { onset (months) }\end{array}$ & $11.46 \pm 1.68$ & $10.69 \pm 1.24$ & 0.107 \\
\hline $\begin{array}{c}\text { Side of hemiplegia } \\
\text { (Right/Left) }\end{array}$ & $(7 / 13)$ & $(6 / 14)$ & ----- \\
\hline $\begin{array}{c}\text { Stroke type [n (\%)] } \\
\text { Ischemic } \\
\text { Hemorrhagic }\end{array}$ & {$[9(45.00)]$} & {$[8(40.00)]$} & ------ \\
\hline
\end{tabular}

\pm SD: Standard Deviation, $\mathrm{P}>0.05$ Non-significant

The results revealed that, there was a significant decrease in MAS scores of the wrist flexors muscles post treatment from $(3.60 \pm 0.25)$ to $(2.50 \pm 0.12)$ for group A and from $(3.55 \pm 0.36)$ to $(2.04 \pm 0.11)$ for group B. Also the MAS scores of the finger flexors muscles was significantly decreased post treatment from $(3.28 \pm 0.64)$ to (1.70 \pm 0.16$)$ for group $A$ and from $(3.19 \pm 0.57)$ to $(1.35 \pm 0.14)$ for group B. The ROM was significantly increased post treatment from $(48.46 \pm 2.09)$ to $(70.02 \pm 3.23)$ for group $A$ and from $(49.15 \pm 1.95)$ to $(79.13 \pm 3.42)$ for group $B$. Moreover, the results revealed that, there was a significant difference between both groups in the MAS scores and ROM values as $(P=0.001)$. Regarding to VAS scores, the results revealed that, there was a significant decreased in VAS post treatment from $(5.73 \pm 0.62)$ to $(2.84 \pm 0.25)$ 
for group $A$ and from $(5.56 \pm 0.59)$ to $(2.73 \pm 0.24)$ for group $B$. While there was no significance difference between both group in VAS values as $(P=0.163)$ as shown in table (2).

Table 2: Comparing mean values for the measured outcomes for both groups.

\begin{tabular}{|c|c|c|c|c|c|c|}
\hline \multirow{2}{*}{ Parameter } & \multicolumn{3}{|c|}{ Pre-treatment } & \multicolumn{3}{c|}{ Post-treatment } \\
\cline { 2 - 7 } & $\begin{array}{c}\text { Group } \\
\text { (A) }\end{array}$ & $\begin{array}{c}\text { Group } \\
\text { (B) }\end{array}$ & P-value & $\begin{array}{c}\text { Group } \\
\text { (A) }\end{array}$ & $\begin{array}{c}\text { Group } \\
\text { (B) }\end{array}$ & P-value \\
\hline $\begin{array}{c}\text { Ashworth wrist } \\
\text { flexors }\end{array}$ & $3.60 \pm 0.25$ & $3.55 \pm 0.36$ & 0.612 & $2.50 \pm 0.12$ & $2.04 \pm 0.11$ & $0.001^{*}$ \\
\hline $\begin{array}{c}\text { Ashworth finger } \\
\text { flexors }\end{array}$ & $3.28 \pm 0.64$ & $3.19 \pm 0.57$ & 0.641 & $1.70 \pm 0.16$ & $1.35 \pm 0.14$ & $0.001^{*}$ \\
\hline $\begin{array}{c}\text { Range of motion } \\
\text { Rain intensity } \\
\text { (VAS) }\end{array}$ & $48.46 \pm 2.09$ & $49.15 \pm 1.95$ & 0.287 & $70.02 \pm 3.23$ & $79.13 \pm 3.42$ & $0.001^{*}$ \\
\hline
\end{tabular}

\pm SD: Standard Deviation, * $\mathrm{P}<0.05$ Significance

\section{DISCUSSION}

The purpose of the study was to compare the effect of two different energy levels of radial SWT on spastic muscles of the hand and wrist in patients affected by stroke. The principal findings of the present study showed that, both energy levels used during treatment resulted in a statistical significant decrease in the level of spasticity as indicated by the MAS scores and also, there was a statistical significant increase in the ROM values for both groups. Furthermore, the medium energy level (4 bar intensity) was better than the low energy level ( 2 bar intensity), as there was a statistical significance difference between both groups in the values of MAS and ROM. Regarding to the pain intensity level, it showed a statistical significant decrease for both groups as indicated by the VAS values but without significance difference between the two energy levels used during the treatment.

The results of present study were in agreement with previous studies that showed that radial SWT has a positive effect on spasticity in patients with stroke and cerebral palsy $[11,20-$ $22,29]$. Standard guidelines for the use of SWT on soft tissue have not been established. However repeated sessions of radial SWT result in a more noticeable and longer-lasting effect [22]. Radial SWT is characterized by having a larger therapeutic area compared with focused SWT. So, radial SWT is more suitable for treating spasticity because it can be applied to the whole muscle belly rather than a small spot in the muscle $[11,29]$.
The mechanisms underlying the beneficial effects of SWT on spasticity are still unclear. Previous studies have proposed that SWT may affect the production of nitric oxides (NO) [30], modify spinal cord excitability [31], or affect the Golgi tendon organ [14] or mechanical vibration [11]. NO, which is generated by SWT, is involved in neurotrans-mission, memory formation, synaptic plasticity in the central nervous system and in the formation of neuromuscular junctions in the peripheral nervous system. So, NO seems to play important roles in spasticity-reduction mechanisms [32,33]. Kenmoku et al. observed rapid degeneration of acetylcholine receptors after SWT application and pointed out that these consequences were very similar to those of a neuromuscular transmission inhibitor like botulinum toxin. However, unlike botulinum toxin, no obvious weakness in the target muscle [34].

Chronic spasticity itself would further worsen joint resistance through fibrosis of inactive connective tissue due to structural and mechanical changes in the muscle [35]. So, reducing the stiffening of connective tissue caused by fibrosis of chronic hypertonic muscles would diminish spasticity [11]. Mechanical and physical impact on tissues exposed to SWT has been found to depend on energy flux density and these tissues could convert SWT stimulation into biochemical signals which leads to cell responses and increased protein synthesis [36]. The results of the current study may suggests that, the mechanical load impacted on the treated tissues with the medium energy level ( 4 bars intensity) was greater due to increased pressure compared with the low energy level ( 2 bars intensity) leading to overstimulation effect of the treated tissues than the low energy level.

\section{CONCLUSION}

Radial SWT is an effective therapeutic tool in reducing flexor spasticity of the wrist and hand in patients with stroke. Moreover, the medium energy level (4 bars intensity) was superior to the low energy level ( 2 bars intensity) in regarding to the measured treatment outcomes.

Ethical clearance: The authors certify that this study involving human subjects is in accordance with Helsinki declaration of 1975 as revised in 2008. 


\section{ACKNOWLEDGEMENTS}

The researchers are indebted to Cairo University, Egypt, Faculty of Physical Therapy and National Institute of Neuromotor System for their permission to commencement the study and to the participants.

\section{Conflicts of interest: None}

\section{REFERENCES}

[1]. Lai SM, Studenski S, Duncan PW, et al. Persisting consequences of stroke measured by the Stroke Impact Scale. Stroke. 2002; 33:1840-1844.

[2]. Langhorne P, Bernhardt J, Kwakkel G. Stroke rehabilitation. The Lance. 2011; 377: 1693-1702.

[3]. Duncan PW, Zorowitz R, Bates B, et al. Management of adult stroke rehabilitation care: a clinical practice guideline. Stroke. 2005; 36:100-143.

[4]. Watkins CL, Leathley MJ, Gregson JM, et al. Prevalence of spasticity post stroke. Clin Rehabil. 2002; 16:515-522.

[5]. Francisco GE, McGuire JR. Poststroke spasticity management. Stroke. 2012; 43:3132-3136.

[6]. Stevenson VL. Rehabilitation in practice: spasticity management. Clin Rehabil 2010; 24:293-304.

[7]. Brashear A, Gordon MF, Elovic E, et al. Botox poststroke spasticity study group. Intramuscular injection of botulinum toxin for the treatment of wrist and finger spasticity after stroke. N Engl J Med. 2002; 347:395- 400.

[8]. Simpson DM, Alexander DN, O'Brien CF, et al. Botulinum toxin type $A$ in the treatment of upper limb spasticity: a randomized double blind, placebo controlled trial. Neurology. 1996; 46:1306 -1310.

[9]. Lagalla G, Danni M, Reiter F, et al. Post stroke spasticity management with repeated botulinum injections in the upper limb. Am J Phys Med Rehabil. 2000; 79:377-384.

[10]. Smith SJ, Ellis E, White S, et al. Double blind placebo controlled study of botulinum toxin in upper limb spasticity after stroke or head injury. Clin Rehabil. 2000; 14:5-13.

[11]. Manganotti P, Amelio E. Long-term effect of shock wave therapy on upper limb hypertonia in patients affected by stroke. Stroke 2005; 36: 1967-1971.

[12]. Moon SW, Kim JH, Jung MJ, et al. The effect of extracorporeal shock wave therapy on lower limb spasticity in subacute stroke patients. Ann Rehabil Med 2013; 37(4):461-470.

[13]. Sohn MK, Cho KH, Kim YJ, et al. Spasticity and electrophysiologic changes after extracorporeal shock wave therapy on gastrocnemius. Ann Rehabil Med 2011; 35:599-604.

[14]. Bae H, Lee JM, Lee KH. The effects of extracorporeal shock wave therapy on spasticity in chronic stroke patients. J Korean Acad Rehabil Med 2010; 34:6639.

[15]. Yoo SD, Kim HS, Jung PK. The effect of shock wave therapy on upper limb spasticity in the patients with stroke. J Korean Acad Rehabil Med 2008;32: 406-10.

[16]. Troncati F, Paci M, Myftari T, et al. Extracorporeal Shock Wave Therapy reduces upper limb spasticity and improves motricity in patients with chronic hemiplegia: a case series. NeuroRehabilitation. 2013; 33:399-405.

[17]. Santamato A, Micello MF, Panza F, et al. Extracorporeal shock wave therapy for the treatment of poststroke plantar-flexor muscles spasticity: a prospective open-label study. Top Stroke Rehabil. 2014; 21:S17-S24.

[18]. Daliri SS, Forogh B, Emami Razavi SZ, et al. A single blind, clinical trial to investigate the effects of a single session extracorporeal shock wave therapy on wrist flexor spasticity after stroke. NeuroRehabilitation. 2015; 36:67-72.

[19]. Lohrer H, Nauck T, Dorn-Lange NV et al. Comparison of radial versus focused extracorporeal shock waves in plantar fasciitis using functional measures. Foot Ankle Int 2010; 31: 1-9.

[20]. Vidal X, Morral A, Costa L, et al. Radial extracorporeal shock wave therapy in the treatment of spasticity in cerebral palsy: a randomized, placebo-controlled clinical trial. Neuro Rehabil 2011; 29: 413419.

[21]. Kim YW, Shin JC, Yoon JG, et al. Usefulness of radial extracorporeal shock wave therapy for the spasticity of the subscapularis in patients with stroke: a pilot study. Chin Med J (Engl). 2013; 126:4638-4643.

[22]. Li TY, Chang CY, Chou YC et al. Effect of radial shock wave therapy on spasticity of the upper limb in patients with chronic stroke. Medicine. 2016; 95(18): e3544.

[23]. Aqil A, Siddiqui M, Solan M, et al. Extracorporeal shock wave therapy is effective in treating chronic plantar fasciitis: A Meta-analysis of RCTs. Clin Orthop Relat Res. 2013; 471:3645-3652.

[24]. Carey MA, Laird DE, Murray KA et al. Reliability, validity, and clinical usability of a digital goniometer. Journal of Prevention, Assessment and Rehabilitation. 2010; 36(1): 55-66.

[25]. Li D, Puntillo K, Miaskowski C. A review of objective pain measures for use with critical care adult patients unable to self-report. Journal of Pain 2008; 9 (1): 2-10.

[26]. Breivik H, Borchgrevink PC, Allen SM et al. Assessment of pain. British Journal of Anesthesia 2008; 101 (1):17-24.

[27]. Allison SC, Abraham LD. Sensitivity of qualitative and quantitative spasticity measures to clinical treatment with cryotherapy. International Journal of Rehabilitation Research. 2001: 24 (1): 15-24.

[28]. Gregson JM, Leathley M, Moore AP et al. Reliability of the tone assessment scale and the Modified Ashworth Scale as clinical tools for assessing post stroke spasticity. Archives of Physical Medicine and Rehabilitation. 1999:80 (9): 1013-1016.

[29]. Amelio E, Manganotti P. Effect of shock wave stimulation on hypertonic plantar flexor muscles in patients with cerebral palsy: a placebo-controlled 
study. J Rehabil Med. 2010; 42:339-343.

[30]. Mariotto S, Cavalieri E, Amelio E, et al. Extracorporeal shock waves: from lithotripsy to anti-inflammatory action by NO production. Nitric Oxide. 2005; 12:89-96.

[31]. Leone JA, Kukulka CG. Effects of tendon pressure on alpha motor neuron excitability in patients with stroke. Phys Ther. 1988; 68: 475-480.

[32]. Mariotto S, Menegazzi M, Suzuki H.: Biochemical aspects of nitric oxide. Curr Pharm Des 2004; 10:1627-1645.

[33]. Mariotto S, de Prati AC, Cavalieri E, et al. Extracorporeal shock wave therapy in inflammatory diseases: molecular mechanism that triggers anti-inflammatory action. Curr Med Chem. 2009; 16:23662372.
[34]. Kenmoku T, Ochiai N, Ohtori S, et al. Nakagawa K, et al.: Degeneration and recovery of the neuromuscular junction after application of extracorporeal shock wave therapy. J Orthop Res 2012; 30:16601665.

[35]. Lagalla G, Danni M, Reiter F, et al. Post-stroke spasticity management with repeated botulinum toxin injections in the upper limb. Am J Phys Med Rehabil. 2000; 79:377-384.

[36]. Orhan Z, Cam K, Alper M, et al. The effects of extracorporeal shock waves on the rat Achilles tendon: is there a critical dose for tissue injury? Arch Orthop Trauma Surg. 2004; 124(9): 631-635.

\footnotetext{
How to cite this article:

Khaled Z. Fouda, Waleed T. Mansour. EFFECT OF DIFFERENT ENERGY LEVELS

OF RADIAL SHOCK WAVE THERAPY ON SPASTICITY IN PATIENTS WITH

STROKE. Int J Physiother Res 2018;6(1):2613-2618. DOI: 10.16965/ ijpr.2017.264
} 